\title{
Science and Technology Indonesia
} e-ISSN:2580-4391 p-ISSN:2580-4405

Vol. 6, No. 3, July 2021

Research Paper

\section{The Ability of Composite Ni/Al-carbon based Material Toward Readsorption of Iron(II) in Aqueous Solution}

\author{
Normah ${ }^{1}$, Neza Rahayu Palapa ${ }^{3}$, Tarmizi Taher ${ }^{2,4}$, Risfidian Mohadi ${ }^{3}$, Hasja Paluta Utami ${ }^{4}$, Aldes Lesbani $i^{1,3,4^{*}}$

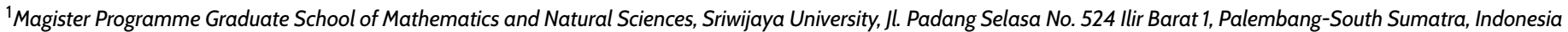

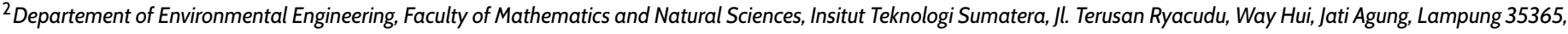 \\ Indonesia \\ ${ }^{3}$ Graduate School of Faculty Mathematics and Natural Sciences, Sriwijaya University, Jl. Padang Selasa No. 524 Ilir Barat 1, Palembang-South Sumatra, Indonesia

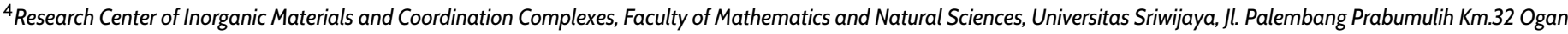 \\ Ilir 30662, Indonesia \\ *Corresponding author: aldeslesbani@pps.unsri.ac.id
}

\begin{abstract}
In this research, NiAl-LDH was synthesized using the coprecipitation method and modified with biochar and graphite to produce NiAlbiochar and NiAl-graphite composite materials. The adsorbent that has been synthesized is used for the application of adsorption of $\mathrm{Fe}$ (II) ions in aqueous solution. The resulting material was characterized by XRD (X-ray Diffraction) analysis, spectrophotometer FT-IR, BET analysis for determine the specific surface area and TG-DTA analysis. XRD diffractogram showed that the NiAl-Biochar and $\mathrm{NiAl-graphite} \mathrm{composite} \mathrm{material} \mathrm{had} \mathrm{the} \mathrm{diffraction} \mathrm{pattern} \mathrm{characteristic} \mathrm{of} \mathrm{the} \mathrm{precursor.} \mathrm{LDH}$ that has been modified will have a larger surface area than the precursor. The surface area of NiAl-biochar reaches $438.942 \mathrm{~m}^{2} / g$ and the surface area of NiAl-graphite reaches $21.595 \mathrm{~m}^{2} / \mathrm{g}$. This composite material supports adsorbents with a large adsorption capacity to adsorb metals. Adsorption of Fe (II) using NiAl-Biochar and NiAl-graphite was stable for five regeneration cycles (<75.30\%). The Fe(II) ion adsorption process tends to follow the Langmuir isotherm model which has a maximum capacity value (Qmax) of NiAl-Biochar composite material reaching 20 times with a value of $243.902 \mathrm{mg} / \mathrm{g}$ and the NiAl-graphite composite reaching $72.464 \mathrm{mg} / \mathrm{g}$, so that the carbon-based composite material is considered effective. adsorbent to remove Fe(II) ion and can increase the stability of the structure for adsorption regeneration. The results of the analysis of thermodynamic parameters showed that the adsorption process was endothermic, took place spontaneously and the solid-liquid phase interface increased according to the increasing degree of disorder.
\end{abstract}

Keywords

Layered Double Hydroxide, Composite, Biochar, Graphite, Iron

Received: 22 March 2021, Accepted: 13 June 2021

https://doi.org/10.26554/sti.2021.6.3.156-165

\section{INTRODUCTION}

LDHs are a class of anionic clays or hydrotalcite (Hu et al., 2019a). The layered structure of LDH is based on a sheet like brucite which has a positive charge on the surface of the layer and a negative charge between the layers due to the presence of anions and water molecules (Cao et al., 2016). LDHs have the formula $\left[\mathrm{M}_{(1-x)}^{2+} \mathrm{M}^{3+x}(\mathrm{OH})_{2}\right]^{x+}\left[\mathrm{A}_{x / n}^{n-} \cdot \mathrm{mH}_{2} \mathrm{O}\right]$ where $\mathrm{M}^{2+}$ and $\mathrm{M}^{3+}$ is a divalent metal ion and trivalent metal ion. $\mathrm{A}^{n-}$ indicates organic or inorganic anions with n- valence (Hu et al., 2019a). In addition, LDH has been known for more than 150 years for its distinctive 2D flat structure and has studied many of the most advanced functional materials used in materials, energy sciences and environmental (Cao et al., 2016). LDH has many interesting properties, such as compositional flexibil- ity (Taher et al., 2019), anion exchange (Lesbani et al., 2021), biocompatibility (Cao et al., 2016), high porosity and surface area (dos Santos Lins et al., 2019). Such structure and characteristics give wide application of $\mathrm{LDH}$ as a catalyst (Hu et al., 2019b), adsorbent (Lesbani et al., 2021) and ion exchanger (Gascho et al., 2019).

Recently, LDHs have been studied to remove organic, inorganic and heavy metal pollutants. The application of LDH as an adsorbent agent has several drawbacks such as a difficult regeneration process because it can undergo exfoliation (dos Santos Lins et al., 2019) and aggregate formation which limits its widespread use (Tan et al., 2019). Therefore, its use is more effective as a composite by adding supporting material to increase layer integrity, such as activated carbon (dos Santos Lins et al., 2019), biochar (Tan et al., 2019) and graphite 


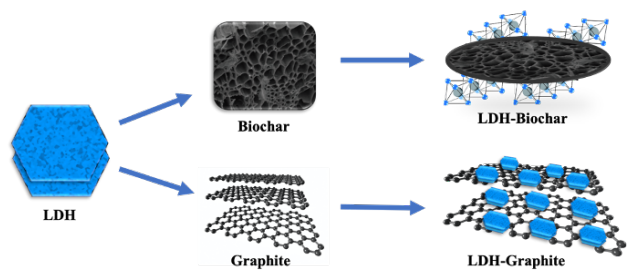

Figure 1. Schematic illustration of preparing the composite LDH-Biochar and LDH-Graphite

(Lee et al., 2018). As introduced, biochar and graphite are attractive materials with interesting properties.

According to Lesbani et al. (2021) biochar is one of the promising supporting materials as an LDH matrix. Organic compounds or biomass are produced through a pyrolysis process that uses high temperatures. The porous biochar acts as an ideal support matrix providing a large reactive area for effective metal hydroxide decoration (Zubair et al., 2017). According to Tan et al. (2019) LDH can be made into a composite by combining two different materials and supporting material in the form of biochar and can improve the ability and adsorption properties to remove pollutants. Apart from that, graphite can also be combined with LDH. In recent years, graphite is considered to be a very efficient adsorbent. Linghu et al. (2017a) reported that $\mathrm{LDH} /$ graphite composites can be used as excellent adsorbents. The graphite contribution in the composites significantly improves its adsorption performance. According to Hu et al. (2020) layered double hydroxides composite with carbon support can effectively prevent agglomeration and increase the specific surface area of the adsorbent produced to provide more active sites to improve the adsorption performance to remove pollutants.

Based on research by Hu et al. (2020) the surface area of $\mathrm{Ni} / \mathrm{Fe}$-carbon composites has doubled to reach $232 \mathrm{~m}^{2} / \mathrm{g}$, while $\mathrm{Ni} / \mathrm{Fe} \mathrm{LDH}$ has a surface area of $108 \mathrm{~m}^{2} / \mathrm{g}$. According to Wang et al. (2016) reported the large specific surface area of $\mathrm{LDH} /$ carbon composites can increase the adsorption capacity to remove As(V) metal from $156 \mathrm{mg} / \mathrm{g}$ to $438 \mathrm{mg} / \mathrm{g}$. According to Tyas et al. (2018) the ability to regenerate is more stable with composite materials. Alagha et al. (2020) reported that biochar$\mathrm{Mg} / \mathrm{Al}$ composites have the potential for repeated use in the phosphate adsorption process and the regeneration process has decreased which is not too significant after five cycles of $92 \%$.

In this study, NiAl-LDH was composited with biochar and graphite using the coprecipitation method which resulted in $\mathrm{NiAl}$-Biochar and NiAl-graphite composites. The material is applied as an adsorbent to remove $\mathrm{Fe}(\mathrm{II})$ ion contaminants. The prepared materials were characterized using XRD, FTIR, BET and TG-DTA analysis. Application as an adsorbent, this research carried out the adsorption process with regeneration studies and adsorption was carried out with isotherm and thermodynamic parameters.

\section{EXPERIMENTAL SECTION}

\subsection{Material}

The precursors $\mathrm{Al}\left(\mathrm{NO}_{3}\right)_{3} \cdot 9 \mathrm{H}_{2} \mathrm{O} 99 \%$ (aluminum nitrate nonahydrate), $\mathrm{FeCl}_{2} \cdot 4 \mathrm{H}_{2} \mathrm{O} 99 \%$ (iron(II) chloride), $\mathrm{Ni}\left(\mathrm{NO}_{3}\right)_{2}$. $3 \mathrm{H}_{2} \mathrm{O} 99 \%$ (nickel nitrate trihydrate), $\mathrm{NaOH} 99 \%$ (sodium hydroxide), and $\mathrm{HCl} 37 \%$ (hydrochloric acid) were purchased from Merck and Sigma-Aldrich. All precursors were utilized as received without further purification. In this study, rice husks obtained from rice mills are used as a precursor for biochar and graphite by Bukataorganics Indonesian. Material characterization was carried out with X-ray Diffraction Rigaku miniflex-6000. Material is scanned from $5-80^{\circ}$ with a scanning speed of $1 \%$ min. Materials were analyzed using FTIR Shimadzu Prestige-2 and using KBr pellets at wavenumbers around 400-4000 $\mathrm{cm}^{-1}$. Adsorption-desorption of $\mathrm{N}_{2}$ was carried out using Quantachrome Micrometic ASAP to determine the pore volume, pore diameter and specific surface area of the material. Analysis of $\mathrm{Fe}(\mathrm{II})$ ion concentration complexed with 1,10-phenanthroline and analyzed using a spectrophotometer 1800 PC UV-Visible Biobase BK-UV Spectrophotometer with a wavelength at a maximum absorbance of $513 \mathrm{~nm}$.

\subsection{Methods}

\subsubsection{Synthesis NiAl-LDH}

Synthesis of NiAl-LDH by coprecipitation method (Kovalenko et al., 2017). $100 \mathrm{~mL}$ of $\mathrm{Ni}\left(\mathrm{NO}_{3}\right)_{2} \cdot 3 \mathrm{H}_{2} \mathrm{O}(0.75 \mathrm{M})$ solution mixed with $100 \mathrm{~mL}$ of $\mathrm{Al}\left(\mathrm{NO}_{3}\right)_{3} \cdot 9 \mathrm{H}_{2} \mathrm{O}(0.25 \mathrm{M})$ (molar ratio $3: 1$ ) in a beaker. The mixture was added $50 \mathrm{~mL}$ of $2 \mathrm{M}$ $\mathrm{NaOH}$ until it reached $\mathrm{pH} 10$. The mixture was stirred until homogeneous and kept for 20 hours at a temperature of $80^{\circ} \mathrm{C}$ until a precipitate was formed. Then filtered using a vacuum, rinsed with distilled water, and dried at $110^{\circ} \mathrm{C}$ to dry.

\subsubsection{Preparation of Composite NiAl-Biochar LDH}

The synthesis of NiAl-Biochar LDH composites was made using the coprecipitation method (Palapa et al., 2020c) carried

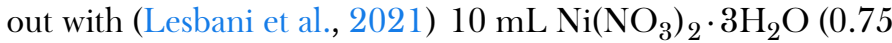
M) solution was mixed with $10 \mathrm{~mL} \mathrm{Al}\left(\mathrm{NO}_{3}\right)_{3} \cdot 9 \mathrm{H}_{2} \mathrm{O}(0.25$ $\mathrm{M})$ and stirred until homogeneous. The resulting mixture was stirred and added with $1 \mathrm{~g}$ of biochar from the rice husk precursor. The mixture was added with $2 \mathrm{M} \mathrm{NaOH}$ until it reached $\mathrm{pH} 10$. The solution mixture was stirred and kept for 3 days at $80^{\circ} \mathrm{C}$. The composite was filtered, rinsed, and dried at $40^{\circ} \mathrm{C}$ to dryness.

\subsubsection{Preparation of Composite NiAl-Graphite LDH}

The method is the same as for the preparation of NiAl-Biochar composites (Cao et al., 2016). $10 \mathrm{~mL} \mathrm{Ni(}\left(\mathrm{NO}_{3}\right)_{2} \cdot 3 \mathrm{H}_{2} \mathrm{O}(0.75$ M) solution and $10 \mathrm{~mL} \mathrm{Al}\left(\mathrm{NO}_{3}\right)_{3} \cdot 9 \mathrm{H}_{2} \mathrm{O}(0.25 \mathrm{M})$ were mixed and stirred until homogeneous. The resulting mixture was added with $2 \mathrm{M}$ of $\mathrm{NaOH}$ until it reached $\mathrm{pH} 10$ and added with $1 \mathrm{~g}$ of graphite. The mixture was treated in the same way as the NiAl-Biochar composite. 


\subsubsection{Batch adsorption studies}

Adsorption studies through the regeneration process, isotherm and thermodynamic parameters. Firstly, regeneration is carried out using an ultrasonic instrument. Adsorption of 20 $\mathrm{mL}$ of $100 \mathrm{mg} / \mathrm{L}$ of $\mathrm{Fe}(\mathrm{II})$ solution, plus $0.2 \mathrm{~g}$ of adsorbent and shaker for 3 hours. After the adsorption process, the desorption process is carried out using water. The desorption process was carried out with the adsorbent that had been used for the adsorption process and $0.01 \mathrm{~g}$ was taken, each added $10 \mathrm{~mL}$ of reagent and shaken for 2 hours. The regeneration process uses used adsorbents. The solution was measured using a UV-Vis spectrophotometer after being complexed with 1,10phenanthroline. The regeneration process is carried out in seven cycles with the same procedure. Secondly, the isotherm and thermodynamic parameters of the adsorption were carried out with an initial concentration of $20 \mathrm{~mL}$ of $\mathrm{Fe}$ (II) solution $(10-50) \mathrm{mg} / \mathrm{L}$, with the addition of $0.02 \mathrm{~g}$ of adsorbent and shaken for 120 minutes and using a variation of the adsorption temperature $\left(30,40,50\right.$, and $\left.60^{\circ} \mathrm{C}\right)$. Third, the Fe(II) solution is mixed with $\mathrm{Ni}$ (II) metal with a concentration of $10 \mathrm{mg} / \mathrm{L}$ then adsorbed with time variations of 200 minutes. The final concentration of $\mathrm{Fe}(\mathrm{II})$ was analyzed at a wavelength of 513 $\mathrm{nm}$ using a UV-Vis Spectrophotometer after being complexed with 1,10-phenanthroline.

\section{RESULTS AND DISCUSSION}

\subsection{Characterization of the adsorbent}

XRD was used to analysis the structure of the material obtained. The XRD patterns of NiAl-LDH, Biochar, NiAl-Biochar and Graphite, and NiAl-Graphite are shown in Figure 2. The XRD patterns of NiAl-LDH in Figure 2 (a) show indications of hydrotalcite according to JCPDS No.15-0087 (Wang et al., 2016). A typical principal diffraction peak is seen at $2 \theta=11.7^{\circ}$, $23.5^{\circ}, 35.1^{\circ}, 39.7^{\circ}, 47.3^{\circ}, 61.2^{\circ}$, and $62.5^{\circ}$ correspond to the crystal plane (003), (006), (012), (015), (018), (110) and (113) from NiAl-LDH, ensuring that the synthesis of NiAl-LDH is successful (Hu et al., 2019a). The XRD pattern of Biochar in Figure 2(b) shows that Biochar has an angle of $2 \theta=23^{\circ}(002)$. (Mon, 2018) reported that the diffraction peaks in Biochar were wide, indicating that biochar has amorphous silica. Figure 2(c) shows the NiAl-Biochar pattern associated with NiAl-LDH with a diffraction angle of $11.60^{\circ}$ and a biochar relationship with a diffraction angle of $23^{\circ}$. According to (Tan et al., 2019) the NiAl-Biochar composite pattern has a decreased intensity due to the amorphous nature of biochar.

Figure 2(d) shows a graphite diffractogram. According to Gascho et al. (2019) graphite has two characteristic peaks at $2 \theta$ $=26^{\circ}(002)$ and $55^{\circ}(004)$. In the graphite pattern Figure $2(\mathrm{~d})$ only has a peak (002) at $2 \theta=26^{\circ}$ (Gascho et al., 2019) and graphite has high crystallinity with a high peak sharp (Kusrini et al., 2019). NiAl-Graphite is presented in Figure 2(e) which shows that the NiAl-Graphite pattern resembles the characteristics of NiAl-LDH and graphite. The XRD NiAl-Graphite pattern has a peak at $2 \theta=12^{\circ}$ which shows the characteristics

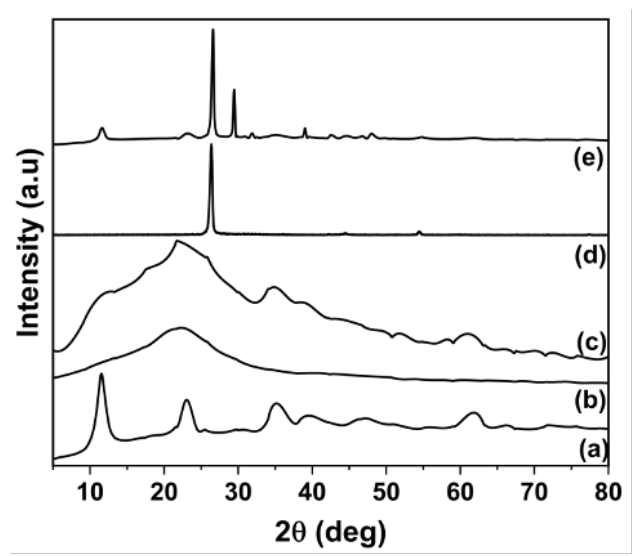

Figure 2. XRD powder patterns of NiAl-LDH (a), Biochar (b), NiAl- Biochar (c), Graphite (d), and NiAl- Graphite (e)

of NiAl-LDH and a peak at $2 \theta=26^{\circ}$ which shows the characteristics of graphite. The pattern of NiAl-Graphite composite shows high intensity which indicates that the material has high crystallinity due to the properties of graphite.

The results of FT-IR analysis of NiAl-LDH, Biochar, NiAlBiochar, Graphite and NiAl-Graphite are shown in Figure 3. The NiAl-LDH spectrum is shown in Figure 3(a), according to Ravuru et al. (2019) wide peak at $3448 \mathrm{~cm}^{-1}$ shows the $\mathrm{O}-\mathrm{H}$ strain of surface hydroxyl groups and water molecules between layers. The peak with $1381 \mathrm{~cm}^{-1}$ is caused by stretching and vibration of $\mathrm{NO}_{3}^{-}$. Vibration corresponding to $1635 \mathrm{~cm}^{-1}$ indicates $\mathrm{O}-\mathrm{H}$ bending. peaks at $794 \mathrm{~cm}^{-1}$ and $587 \mathrm{~cm}^{-1}$ each vibration to $\mathrm{M}-\mathrm{O}$ and $\mathrm{O}-\mathrm{M}-\mathrm{O}$. Figure $3(\mathrm{~b})$ shows the spectrum of biochar. The peak at $3448 \mathrm{~cm}^{-1}$ is thought to originate from the strain vibration of the hydroxyl group. The $2368 \mathrm{~cm}^{-1}$ peak shows the $\mathrm{C}-\mathrm{C}$ strain vibration. The peaks correspond to the aliphatic $-\mathrm{CH}_{2}$ strain vibration and significant $\mathrm{C}=\mathrm{C}$ aromatic peaks appearing at $1095 \mathrm{~cm}^{-1}$ and $798 \mathrm{~cm}^{-1}$ (Palapa et al., 2020b). Figure 3(c) shows the NiAl-Bichar spectrum. The peaks appear at $3448 \mathrm{~cm}^{-1}, 2368 \mathrm{~cm}^{-1}, 1635 \mathrm{~cm}^{-1}, 1381$ $\mathrm{cm}^{-1}, 1095 \mathrm{~cm}^{-1}$ and $798 \mathrm{~cm}^{-1}$. All peaks that appear on NiAlBiochar are NiAl-LDH and biochar vibrations. The graphite spectrum is shown in Figure 3(d). According to Linghu et al. (2017a) peaks at $3432 \mathrm{~cm}^{-1}$ showed O-H vibrations. A peak at $1614 \mathrm{~cm}^{-1}$ is associated with aromatic $\mathrm{C}=\mathrm{C}$ and a peak at 1381 $\mathrm{cm}^{-1}$ indicates a stretch of $\mathrm{C}=\mathrm{O}$ in the carboxylic acid group (Linghu et al., 2017b). Figure 3(e) NiAl-Graphite spectrum appears peaks of $3448 \mathrm{~cm}^{-1}, 1614 \mathrm{~cm}^{-1}, 1381 \mathrm{~cm}^{-1}, 794$ $\mathrm{cm}^{-1}$ showing NiAl-LDH and graphite vibrations.

The BET isotherm is presented in Figure 4. From the figure, it can be seen that the shape of the isotherm is similar to the type IV which is indicated by the presence of a hysteresis loop. This indicates that the gas capillary condensation in the mesopore at relatively high pressure. Loop hysteresis shows H2-type in the presence of bottle-shaped pores with a narrow mouth and a wide body (Ravuru et al., 2019).

The isotherm data are shown in Table 1 . Table 1 shows 

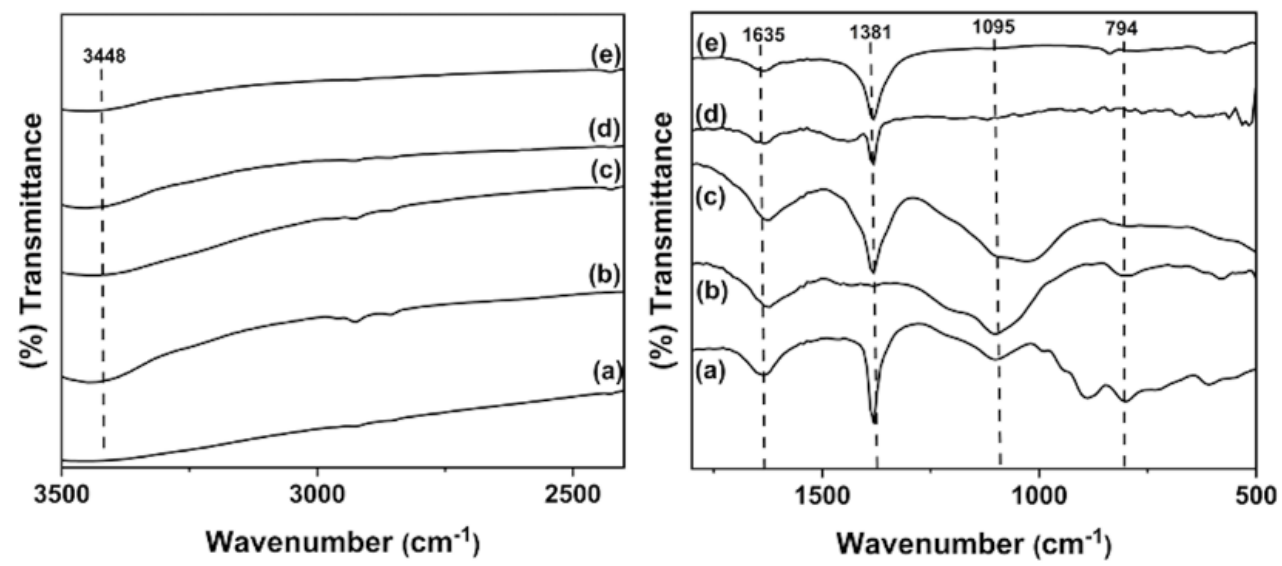

Figure 3. FTIR spectrum of NiAl LDH (a), Biochar (b), NiAl-Biochar (c), Graphite (d), and NiAl- Graphite (e)

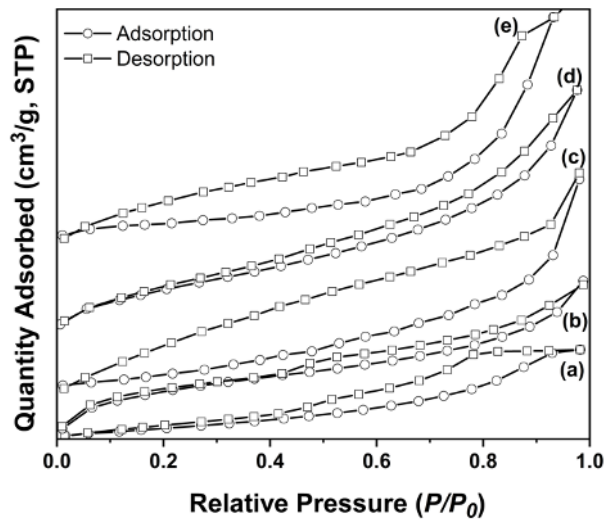

Figure 4. BET profile of NiAl LDH (a), Biochar (b),

NiAl-Biochar (c), Graphite (d), and NiAl- Graphite (e)

that NiAl-biochar and NiAl-graphite have a larger surface area compared to NiAl-LDH, biochar and graphite. NiAl-Biochar has a specific surface area of $438.942 \mathrm{~m}^{2} / \mathrm{g}$ and NiAl-graphite of $21.595 \mathrm{~m}^{2} / \mathrm{g}$. NiAl-biochar surface area has a surface area twenty times that of NiAl-Graphite. This is because biochar and graphite can prevent agglomeration and increase the specific surface area (Lyu et al., 2020).

The thermal behavior of NiAl-LDH, biochar, graphite, $\mathrm{NiAl}$-biochar and NiAl-graphite carried out with nitrogen is presented in Figure 5. It can be seen from Figure 5 (a) which shows that NiAl-LDH has two endothermic peaks at $90^{\circ} \mathrm{C}$ which shows loss of nitrates and loss of air molecules. The peak was at $300^{\circ} \mathrm{C}$ indicating that NiAl-LDH lost water molecules on the interlayer. Figure 5 (b) shows the fact of mass reduction at $400^{\circ} \mathrm{C}$ and at $600^{\circ} \mathrm{C}$ which shows the decomposition of lignin. The decrease in landmass which reaches $800^{\circ} \mathrm{C}$ is insignificant degradation occurs because most of the volatile molecules have undergone pyrolysis (Wazir et al., 2020). Figure 5 (c) shows one endothermic peak at $430^{\circ} \mathrm{C}$ and $510^{\circ} \mathrm{C}$ which indicates that LDH decomposition and oxidation of the biochar material occurs. Figure 5 (d) shows that at a temperature of $760^{\circ} \mathrm{C}$ the graphite material has become graphite oxide. Figure 5 (e) has an endothermic peak at $90^{\circ} \mathrm{C}$ which indicates a loss of water molecules, a peak at $800{ }^{\circ} \mathrm{C}$ indicating that there has been a change to oxides.

\subsubsection{Adsorption}

The results of $\mathrm{Fe}(\mathrm{II})$ ion adsorption regeneration using $\mathrm{NiAl}$ LDH, Biochar, NiAl-Biochar, Graphite, and NiAl-Graphite showned in Figure 6 were carried out seven times. The results showed that the NiAl-biochar and NiAl-Graphite composite materials had a greater adsorption capacity and a more stable regeneration process compared to pure materials. Adsorption of $\mathrm{Fe}(\mathrm{II})$ ion using $\mathrm{NiAl}-\mathrm{Biochar}$ and $\mathrm{NiAl}$-graphite was stable for five regeneration cycles, respectively reaching $91.08 \%-77.26 \%$ and $83.11 \%-75.30 \%$. this is because the process of modifying LDH with carbon-based materials can increase the stability of the structure (Alagha et al., 2020). The figure shows that $\mathrm{NiAl}$-biochar material has a greater adsorption capacity than $\mathrm{NiAl}$-graphite, this is supported by BET analysis data which shows NiAl-biochar has a larger specific surface area. The adsorption capacity of NiAl-LDH, Biochar and graphite has decreased significantly in the regeneration process, this is because the material has an unstable structure which results in exfoliation when used repeatedly (Palapa et al., 2020d) and structural damage. So it can be concluded that LDH modification with carbon-based materials can improve the stability of the LDH structure (Tang et al., 2020).

Thermodynamic parameters were studied through variations in the initial concentration of Fe(II) ions and the adsorption temperature as shown in Figure 7 . Figure 7 shows that the adsorption capacity increases with increasing adsorption temperature used. It can be seen that the adsorption temperature greatly affects the maximum adsorption capacity for $\mathrm{Fe}(\mathrm{II})$ ions, this is because the increase in temperature causes an increase in the number of active sites on the surface and there is an increasing number of interactions between Fe(II) ions and active sites (Dada et al., 2017). 
Table 1. NiAl-LDH performance with different support materials

\begin{tabular}{cccc}
\hline Materials & $\begin{array}{c}\text { Specific Surface } \\
\text { Area }\left(\mathrm{m}^{2} / \mathrm{g}\right)\end{array}$ & $\begin{array}{c}\text { Pore Diameter } \\
(\mathrm{nm}) \mathrm{BJH}\end{array}$ & $\begin{array}{c}\text { Pore Volume } \\
\left(\mathrm{cm}^{3} / \mathrm{mg}\right) \mathrm{BJH}\end{array}$ \\
\hline NiAl-LDH & 15.106 & 2.897 & 0.043 \\
Biochar & 50.936 & 12.089 & 0.025 \\
Graphite & 11.558 & 3.169 & 0.027 \\
NiAl-Biochar & 438.942 & 12.301 & 0.002 \\
NiAl-Graphite & 21.595 & 3.153 & 0.034 \\
\hline
\end{tabular}
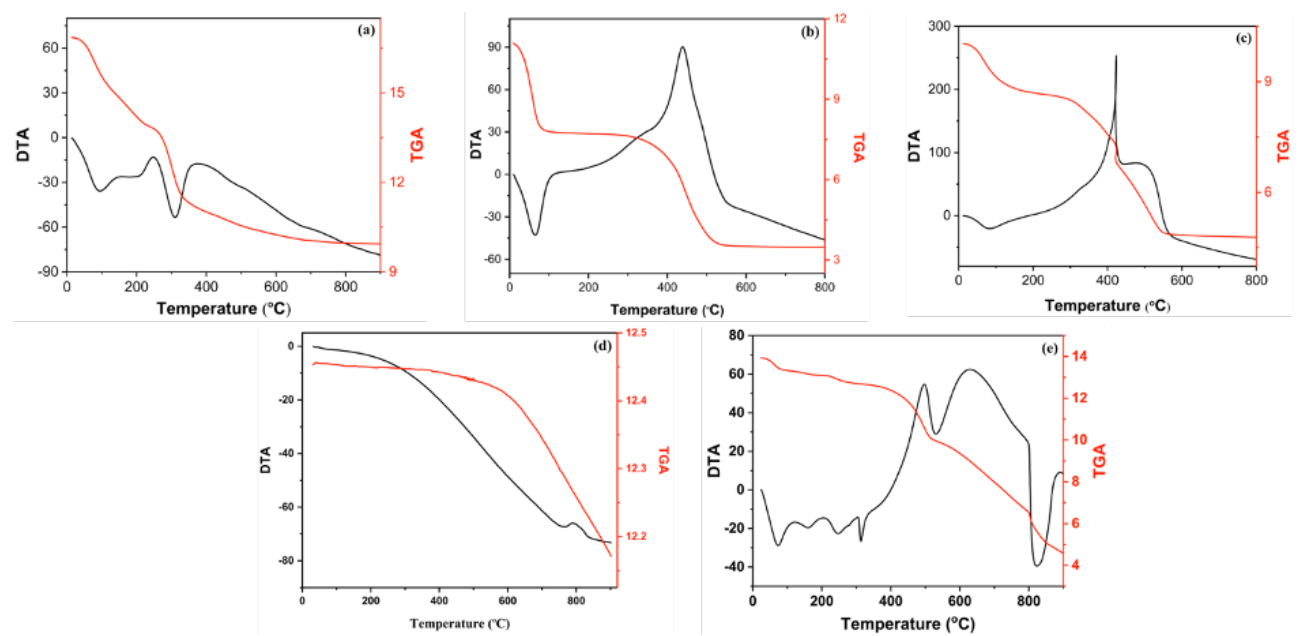

Figure 5. Thermal profile of NiAl-LDH (a), Biochar (b), NiAl- Biochar (c), Graphite (d), and NiAl-Graphite (e)

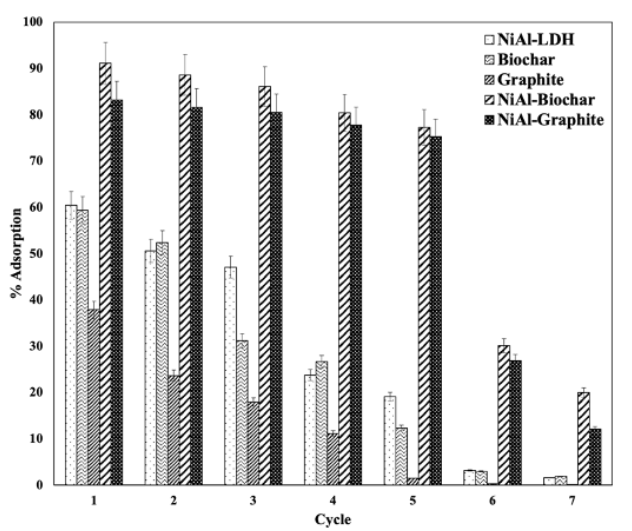

Figure 6. Regeneration $\mathrm{Fe}(\mathrm{II})$ on NiAl LDH, Biochar, NiAlBiochar, Graphite, and NiAl-Graphite

Table 2 shows the results of the calculation of the adsorption isotherm. According to Siregar et al. (2021) isotherm parameters are obtained from the equations of Langmuir and Freundlich. Table 2 shows that the highest value of adsorption capacity (Qmax) in NiAl-Biochar composite material reaches $243.902 \mathrm{mg} / \mathrm{g}$ at a temperature of $333 \mathrm{~K}$ and $\mathrm{NiAl}$-graphite composite reaches $72.464 \mathrm{mg} / \mathrm{g}$, so carbon-based composite materials are considered as an effective adsorbent to remove the $\mathrm{Fe}(\mathrm{II})$ ion. The adsorption capacity of NiAl-biochar and NiAl-graphite has a larger adsorption capacity compared to pure materials, this is supported by the larger surface areas of $\mathrm{NiAl}$-biochar and NiAl-graphite. The larger the surface area, the more active sites available on the surface will increase the performance of the material in the adsorption process ( $\mathrm{Hu}$ et al., 2020) .

The determination of the adsorption isotherm model is seen from the linear regression value which is closer to the value 1. From the data in Table 2 it can be seen that the isotherm model for each adsorbent tends to approach the Langmuir isotherm model with a linear regression value $\mathrm{R}^{2}>0.997$. According to Edet and Ifelebuegu (2020), the Langmuir model explains that monolayer adsorption at different active sites, means that there is no transmigration of the adsorbate in the surface area and assumes a uniform monolayer absorption energy to the adsorbent surface. Dada et al. (2017) assume that in the Langmuir isotherm model there is no interaction between adsorbed adjacent species, the adsorption process only occurs at certain locations located on the active surface site.

The adsorption capacity of several adsorbents to remove Fe(II) metal ions, as well as the adsorbent synthesized in the form of NiAl-LDH, biochar, graphite, NiAl-biochar and NiAlgraphite used in this study is presented in Table 3 . The adsorption capacity of NiAl-LDH composite materials with carbon- 

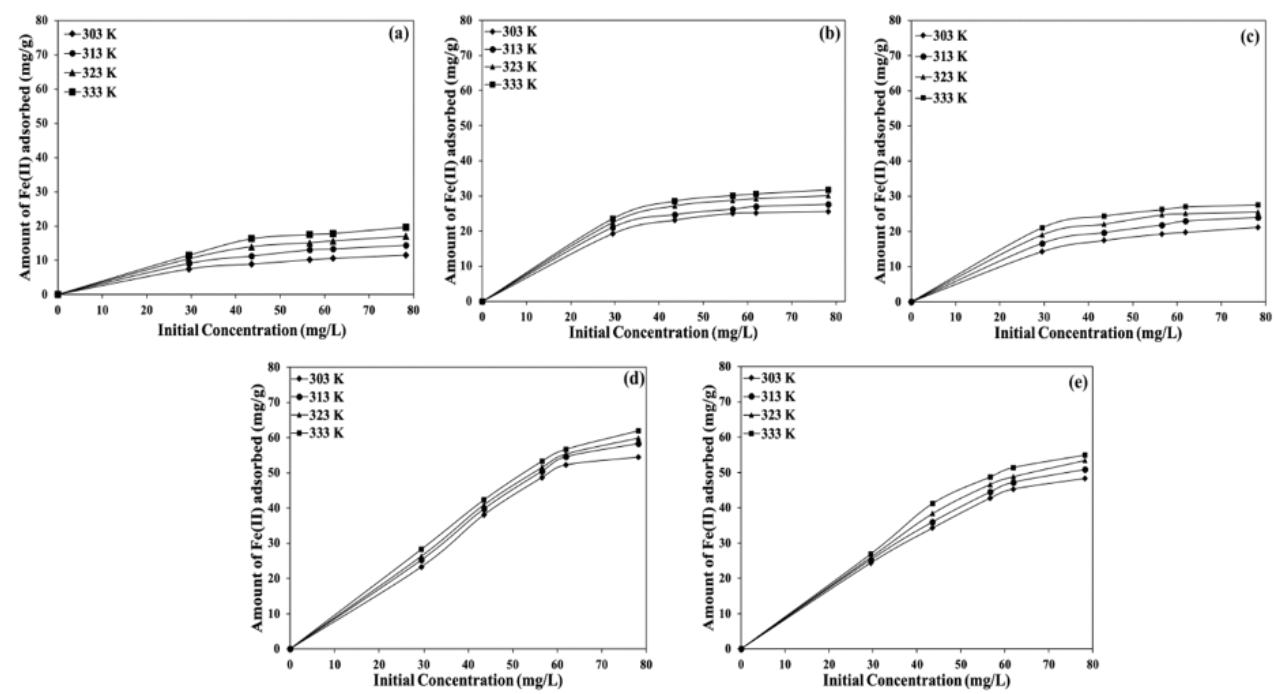

Figure 7. Effect of $\mathrm{Fe}(\mathrm{II})$ concentration on Ni/Al LDH (a), Biochar (b), Graphite (c), NiAl-Biochar (d), and Ni/Al-Graphite (e)

Table 2. Isotherm model of Fe(II) adsorption on Ni/Al LDH, Biochar, Ni/Al- Biochar, Graphite, and Ni/Al-Graphite

\begin{tabular}{|c|c|c|c|c|c|c|}
\hline \multirow{2}{*}{$\mathrm{LDH}$} & \multirow{2}{*}{$\begin{array}{l}\text { Adsorption } \\
\text { Isotherm }\end{array}$} & \multirow{2}{*}{$\begin{array}{c}\text { Adsorption } \\
\text { Constant }\end{array}$} & \multicolumn{4}{|c|}{$\mathrm{T}(\mathrm{K})$} \\
\hline & & & $303 \mathrm{~K}$ & $313 \mathrm{~K}$ & $323 \mathrm{~K}$ & $333 \mathrm{~K}$ \\
\hline \multirow[t]{6}{*}{ NiAl-LDH } & \multirow[t]{3}{*}{ Langmuir } & $Q_{\max }$ & 25.907 & 28.986 & 29.07 & 29.586 \\
\hline & & $\mathrm{kL}$ & 0.078 & 0.09 & 0.17 & 0.272 \\
\hline & & $\mathrm{R}^{2}$ & 0.998 & 0.998 & 0.997 & 0.999 \\
\hline & \multirow[t]{3}{*}{ Freundlich } & $\mathrm{n}$ & 3.092 & 3.494 & 4.456 & 5.811 \\
\hline & & $\mathrm{kF}$ & 5.976 & 7.963 & 11.241 & 14.639 \\
\hline & & $\mathrm{R}^{2}$ & 992 & 0.997 & 0.993 & 0.996 \\
\hline \multirow[t]{6}{*}{ Biochar } & \multirow[t]{3}{*}{ Langmuir } & $Q_{\max }$ & 27.855 & 29.499 & 31.847 & 33.333 \\
\hline & & $\mathrm{kL}$ & 0.242 & 0.284 & 0.34 & 0.38 \\
\hline & & R2 & 0.999 & 0.999 & 0.999 & 0.999 \\
\hline & \multirow[t]{3}{*}{ Freundlich } & $\mathrm{n}$ & 4.615 & 5.838 & 5.807 & 6.317 \\
\hline & & $\mathrm{kF}$ & 11.768 & 14.727 & 16.237 & 17.968 \\
\hline & & $\mathrm{R}^{2}$ & 0.979 & 0.993 & 0.967 & 0.965 \\
\hline \multirow[t]{6}{*}{ Graphite } & \multirow[t]{3}{*}{ Langmuir } & $Q_{\max }$ & 16.026 & 20.161 & 23.095 & 20.534 \\
\hline & & $\mathrm{kL}$ & 0.038 & 0.04 & 0.046 & 0.061 \\
\hline & & R2 & 0.996 & 0.997 & 0.992 & 0.976 \\
\hline & \multirow[t]{3}{*}{ Freundlich } & $\mathrm{n}$ & 2.409 & 2.183 & 2.225 & 2.078 \\
\hline & & $\mathrm{kF}$ & 2.067 & $2 . .282$ & 2.856 & 3.02 \\
\hline & & $\mathrm{R}^{2}$ & 0.998 & 0.995 & 0.946 & 0.889 \\
\hline \multirow[t]{6}{*}{ NiAl-Biochar } & \multirow[t]{3}{*}{ Langmuir } & $Q_{\max }$ & 83.333 & 86.207 & 90.909 & 243.9 \\
\hline & & $\mathrm{kL}$ & 0.033 & 0.208 & 0.029 & 0.266 \\
\hline & & $\mathrm{R}^{2}$ & 0.992 & 0.898 & 0.95 & 0.996 \\
\hline & \multirow[t]{3}{*}{ Freundlich } & $\mathrm{n}$ & 1.029 & 1.196 & 1.75 & 2.743 \\
\hline & & $\mathrm{kF}$ & 5.766 & 10.361 & 18.88 & 32.367 \\
\hline & & $\mathrm{R}^{2}$ & 0.934 & 0.953 & 0.952 & 0.711 \\
\hline \multirow{6}{*}{ NiAl-Graphite } & \multirow{3}{*}{ Langmuir } & $Q_{\max }$ & 57.803 & 61.728 & 62.5 & 72.464 \\
\hline & & $\mathrm{kL}$ & 0.056 & 0.046 & 0.068 & 0.148 \\
\hline & & $\mathrm{R}^{2}$ & 0.991 & 0.994 & 0.993 & 0.992 \\
\hline & \multirow[t]{3}{*}{ Freundlich } & $\mathrm{n}$ & 1.745 & 2.053 & 2.293 & 3.403 \\
\hline & & $\mathrm{kF}$ & 2.616 & 3.963 & 5.349 & 25.864 \\
\hline & & $\mathrm{R}^{2}$ & 0.995 & 0.989 & 0.891 & 0.932 \\
\hline
\end{tabular}


Table 3. Comparison of the adsorption capacity of Fe(II) metal ions with various adsorbents

\begin{tabular}{ccc}
\hline Adsorbent & $\begin{array}{c}\text { Adsorption Capacity } \\
(\mathrm{mg} / \mathrm{g})\end{array}$ & Reference \\
\hline Carbon-MgAl LDH & 80 & (Kundu and Naskar, 2021) \\
Ca/Al LDH & 11.16 & (Taher et al., 2019) \\
Ca/Al- $\left[\alpha-\mathrm{SiW}_{12} \mathrm{O}_{40}\right]$ & 11.93 & (Taher et al., 2019) \\
(Dai et al., 2012) \\
Thiourea Cross-Linked Chitosan & 48.3 & (Radnia et al., 2012) \\
Chitosan & 28.7 & (Mostafa et al., 2014) \\
Co/Mo LDH & 10 & (Zhang et al., 2014) \\
Rice Husk Ash & 6.211 & (Shrestha, 2018) \\
Banana Peel & 33.79 & (Lesbani et al., 2020) \\
(Al-Shahrani, 2013) & This Research \\
Ni/Al LDH intercalated with keggin ion & 36.49 & This Research \\
Bentonite & 7.09 & This Research \\
NiAl-LDH & 29.586 & This Research \\
Biochar & 33.333 & This Research \\
Graphite & 23.095 & \\
NiAl-Biochar & 243.902 & \\
NiAl-Graphite & 72.464 &
\end{tabular}

based materials has capacity which is greater compared to NiAl-LDH before modification. NiAl-Biochar composites have an adsorption capacity of up to two times compared to NiAl-Graphite. This is supported by large data on the surface area of the NiAl-Biochar material, therefore NiAl-Biochar has more active site interactions with Fe(II) metal ions on the adsorbent surface.

In adsorption studies the effect of temperature is an important parameter, this is because several important thermodynamic parameters can be determined such as $\Delta H$ (enthalpy), $\Delta \mathrm{S}$ (entropy) and $\Delta \mathrm{G}$ (Gibbs free energy). The adsorption temperature used in this study was from 303K-333K. Based on the research of Palapa et al. (2020a) thermodynamic results were calculated by The Van't Hoff equation.

Table 4 assumes that the adsorption occurs endothermically because it has a positive $\Delta \mathrm{H}$ value $(\Delta \mathrm{H}=+13,677-25,919$ $\mathrm{kJ} / \mathrm{mol}$ ) and $\Delta \mathrm{H}<84 \mathrm{~kJ} / \mathrm{mol}$ assumes that the adsorption process occurs by physical adsorption. The $\Delta \mathrm{S}$ value is positive (0.052-0.091 J/mol.K) which assumes the degree of irregularity at the solid-liquid interface during the adsorption process of $\mathrm{Fe}$ (II) ion onto the adsorbent surface. the adsorption and desorption processes occur simultaneously in the adsorption process, so the increase in the irregularity of the adsorbate molecules is associated with a dissociative process where during bond breaking (desorption) the energy absorbed is greater than the energy released during bond formation (adsorption). Thus, a positive $\Delta \mathrm{S}$ value indicates that the $\mathrm{Fe}(\mathrm{II})$ ion has a high affinity for the adsorbent, this is because the energy required to break the same bond is greater than the energy required to form a bond with the adsorbent (Antonelli et al., 2020). According to Lafi et al. (2018) negative values on free energy Gibbs $(\Delta G)$ assume that viability, feasibility, spontaneity of adsorption process and adsorbate have high affinity for adsor- bents. In addition, according to Antonelli et al. (2020) with increasing temperature in the adsorption process, the value of $G$ decreases, it indicates that the adsorption process is better carried out at higher temperatures.

\section{CONCLUSIONS}

In this study, NiAl-Biochar and NiAl-Graphite composite materials were successfully synthesized and NiAl-LDH, Biohar, graphite, NiAl-Biochar and NiAl-graphite were applied as an adsorbent to reduce the levels of $\mathrm{Fe}$ (II) metal ions in aqueous solution. The resulting material was characterized and analyzed using XRD analysis, analysis using FT-IR spectrophotometer, BET analysis and TG-DTA analysis to see from the start. Characterization using BET showed that the surface area of NiAlbiochar and NiAl-graphite composites increased as precursors. The surface areas of NiAl-Biochar and NiAl-graphite reached $438.942 \mathrm{~m}^{2} / \mathrm{g}$ and $21.595 \mathrm{~m}^{2} / \mathrm{g}$. This composite material supports adsorbents with a large adsorption capacity to adsorb metals. Adsorption of Fe(II) ion using NiAl-Biochar and NiAlgraphite was stable for five regeneration cycles $<75.30 \%$. The adsorption of $\mathrm{Fe}(\mathrm{II})$ ions on the prepared adsorbent tend to follows the Langmuir adsorption isotherm model with a maximum capacity (Qmax) of the NiAl-Biochar composite material reaching $243.902 \mathrm{mg} / \mathrm{g}$ and the $\mathrm{NiAl}$-graphite composite reaching $72.464 \mathrm{mg} / \mathrm{g}$, so carbon-based composite materials are considered effective. adsorbent to remove Fe(II) ions and can increase the stability of the structure for adsorption regeneration. Thermodynamic data results analysis of the adsorption process occurred endothermic, spontaneously and the degree of irregularity increased in the solid-liquid phase interface. 
Table 4. Thermodynamic parameters of Fe(II) adsorption on Ni/Al LDH, Biochar, Ni/Al- Biochar, Graphite, and Ni/Al-Graphite

\begin{tabular}{cccccc}
\hline \multirow{2}{*}{ Adsorbent } & $\mathrm{T}(\mathrm{K})$ & Qe $(\mathrm{mg} / \mathrm{g})$ & $\begin{array}{c}\Delta \mathrm{H} \\
(\mathrm{kJ} / \mathrm{mol})\end{array}$ & $\begin{array}{c}\Delta \mathrm{S} \\
(\mathrm{J} / \mathrm{mol} . \mathrm{K})\end{array}$ & $\begin{array}{c}\Delta \mathrm{G} \\
(\mathrm{kJ} / \mathrm{mol})\end{array}$ \\
\hline NiAl-LDH & 303 & 15.29 & 25.919 & 0.091 & -1.545 \\
& 313 & 16.603 & & & -2.451 \\
& 323 & 19.079 & & & -3.358 \\
Biochar & 333 & 21.093 & & & -4.264 \\
& 303 & 19.27 & 20.487 & 0.073 & -1.624 \\
& 313 & 21.093 & & & -2.354 \\
Graphite & 323 & 22.426 & & & -3.084 \\
& 333 & 23.515 & & & -3.813 \\
& 313 & 7.488 & 17.712 & 0.066 & -2.373 \\
& 323 & 10.426 & & & -3.036 \\
NiAl-Biochar & 333 & 11.515 & & & -3.699 \\
& 303 & 24.385 & 21.259 & 0.083 & -3.362 \\
& 313 & 25.297 & & & -4.697 \\
& 323 & 25.964 & & & -5.526 \\
NiAl-Graphite & 333 & 26.916 & & & -6.355 \\
& 303 & 54.476 & 13.677 & 0.052 & -2.16 \\
& 313 & 58.359 & & & -2.683 \\
& 333 & 59.946 & & & -3.206 \\
& 331.932 & & & -3.728 \\
\hline
\end{tabular}

\section{ACKNOWLEDGEMENT}

Thanks to Sriwijaya University through the Hibah Profesi No.150/SP2H/LT/DRPM/2021 and thanks to the Laboratory of Inorganic Materials and Complexes of the Faculty of Mathematics and Natural Sciences, Sriwijaya University.

\section{REFERENCES}

Al-Shahrani, S. (2013). Treatment of wastewater contaminated with Fe (II) by Adsorption onto Saudi Activated Bentonite. International Journal of Engineering \& Technology, 13(06); 112

Alagha, O., M. S. Manzar, M. Zubair, I. Anil, N. D. Mu'azu, and A. Qureshi (2020). Comparative Adsorptive Removal of Phosphate and Nitrate from Wastewater Using Biochar$\mathrm{MgAl}$ LDH Nanocomposites: Coexisting Anions Effect and Mechanistic Studies. Nanomaterials, 10(2); 336

Antonelli, R., G. R. P. Malpass, M. G. C. da Silva, and M. G. A. Vieira (2020). Adsorption of ciprofloxacin onto thermally modified bentonite clay: Experimental design, characterization, and adsorbent regeneration. Journal of Environmental Chemical Engineering, 8(6); 104553

Cao, Y., G. Li, and X. Li (2016). Graphene/layered double hydroxide nanocomposite: Properties, synthesis, and applications. Chemical Engineering Journal, 292; 207-223

Dada, A. O., F. A. Adekola, and E. O. Odebunmi (2017). Kinetics, mechanism, isotherm and thermodynamic studies of liquid phase adsorption of $\mathrm{Pb} 2$ onto wood activated car- bon supported zerovalent iron (WAC-ZVI) nanocomposite. Cogent Chemistry, 3(1); 1351653

Dai, J., F. Ren, and C. Tao (2012). Adsorption Behavior of $\mathrm{Fe}(\mathrm{II})$ and $\mathrm{Fe}$ (III) Ions on Thiourea Cross-Linked Chitosan with Fe(III) as Template. Molecules, 17(4); 4388-4399

dos Santos Lins, P. V., D. C. Henrique, A. H. Ide, C. L. de Paiva e Silva Zanta, and L. Meili (2019). Evaluation of caffeine adsorption by MgAl-LDH/biochar composite. Environmental Science and Pollution Research, 26(31); 3180431811

Edet, U. A. and A. O. Ifelebuegu (2020). Kinetics, isotherms, and thermodynamic modeling of the adsorption of phosphates from model wastewater using recycled brick waste. Processes, 8(6); 665

Gascho, J. L. S., S. F. Costa, A. A. C. Recco, and S. H. Pezzin (2019). Graphene Oxide Films Obtained by Vacuum Filtration: X-Ray Diffraction Evidence of Crystalline Reorganization. Journal of Nanomaterials, 2019; 1-12

Hu, H., S. Wageh, A. A. Al-Ghamdi, S. Yang, Z. Tian, B. Cheng, and W. Ho (2020). NiFe-LDH nanosheet/carbon fiber nanocomposite with enhanced anionic dye adsorption performance. Applied Surface Science, 51 1; 145570

Hu, X., P. Li, X. Zhang, B. Yu, C. Lv, N. Zeng, J. Luo, Z. Zhang, J. Song, and Y. Liu (2019a). Ni-based catalyst derived from $\mathrm{NiAl}$ layered double hydroxide for vapor phase catalytic exchange between hydrogen and water. Nanomaterials, 9(12); 1688

Hu, Z., L. Cai, J. Liang, X. Guo, W. Li, and Z. Huang (2019b). 
Green synthesis of expanded graphite/layered double hydroxides nanocomposites and their application in adsorption removal of $\mathrm{Cr}$ (VI) from aqueous solution. Journal of Cleaner Production, 209; 1216-1227

Kovalenko, V., V. Kotok, A. Yeroshkina, and A. Zaychuk (2017). Synthesis and characterisation of dyeintercalated nickelaluminium layereddouble hydroxide as a cosmetic pigment. Eastern-European Journal of Enterprise Technologies, 5(12 (89)); 27-33

Kundu, S. and M. K. Naskar (2021). Carbon-layered double hydroxide nanocomposite for efficient removal of inorganic and organic based water contaminants - unravelling the adsorption mechanism. Materials Advances, 2(11); 3600-3612

Kusrini, E., A. A. Suhrowati, A. Usman, D. V. Degirmenci, and M. Khalil (2019). Synthesis and Characterization of Graphite Oxide, Graphene Oxide and Reduced Graphene Oxide from Graphite Waste using Modified Hummers's Method and Zinc as Reducing Agent. International Journal of Technology, 10(6); 1093

Lafi, R., I. Montasser, and A. Hafiane (2018). Adsorption of congo red dye from aqueous solutions by prepared activated carbon with oxygen-containing functional groups and its regeneration. Adsorption Science \& Technology, 37(1-2); 160181

Lee, I., G. H. Jeong, S. An, S.-W. Kim, and S. Yoon (2018). Facile synthesis of 3D MnNi-layered double hydroxides (LDH)/graphene composites from directly graphites for pseudocapacitor and their electrochemical analysis. Applied Surface Science, 429; 196-202

Lesbani, A., N. R. Palapa, R. J. Sayeri, T. Taher, and N. Hidayati (2021). High Reusability of NiAl LDH/Biochar Composite in the Removal Methylene Blue from Aqueous Solution. Indonesian Journal of Chemistry

Lesbani, A. L., N. Normah, N. R. Palapa, T. Taher, R. Andreas, and R. Mohadi (2020). Removal of Iron(II) Using Ni/Al Layered Double Hydroxide Intercalated with Keggin Ion. Molekul, 15(3); 149

Linghu, W., H. Yang, Y. Sun, G. Sheng, and Y. Huang (2017a). One-pot synthesis of LDH/GO composites as highly effective adsorbents for decontamination of U (VI). ACS Sustainable Chemistry \& Engineering, 5(6); 5608-5616

Linghu, W., H. Yang, Y. Sun, G. Sheng, and Y. Huang (2017b). One-Pot Synthesis of LDH/GO Composites as Highly Effective Adsorbents for Decontamination of U(VI). ACS Sustainable Chemistry \& Engineering, 5(6); 5608-5616

Lyu, H., K. Hu, J. Fan, Y. Ling, Z. Xie, and J. Li (2020). 3D hierarchical layered double hydroxide/carbon spheres composite with hollow structure for high adsorption of dye. Applied Surface Science, 500; 144037

Mon, E. E. (2018). Study on the Silica from Rice Husk Ash by XRD and XRF. Int. J. Sci. Eng. Res, 9(6); 1535-1537

Mostafa, M., A. Bakr, G. Eshaq, and M. Kamel (2014). Novel Co/Mo layered double hydroxide: synthesis and uptake of $\mathrm{Fe}(\mathrm{II})$ from aqueous solutions (Part 1). Desalination and Water Treatment, 56(1); 239-247
Palapa, N. R., R. Mohadi, A. Rachmat, et al. (2020a). Adsorption study of malachite green removal from aqueous solution using $\mathrm{Cu} / \mathrm{M} 3+(\mathrm{M} 3+=\mathrm{Al}, \mathrm{Cr})$ layered double hydroxide. Mediterranean Journal of Chemistry, 10(1); 33-45

Palapa, N. R., T. Taher, R. Mohadi, A. Rachmat, and A. Lesbani (2020b). Preparation of copper aluminum-biochar composite as adsorbent of malachite green in aqueous solution. Chemical Physics

Palapa, N. R., T. Taher, B. R. Rahayu, R. Mohadi, A. Rachmat, and A. Lesbani (2020c). CuAl LDH/Rice Husk Biochar Composite for Enhanced Adsorptive Removal of Cationic Dye from Aqueous Solution. Bulletin of Chemical Reaction Engineering \& Catalysis, 15(2); 525-537

Palapa, N. R., T. Taher, B. R. Rahayu, R. Mohadi, A. Rachmat, and A. Lesbani (2020d). CuAl LDH/Rice Husk Biochar Composite for Enhanced Adsorptive Removal of Cationic Dye from Aqueous Solution. Bulletin of Chemical Reaction Engineering \& Catalysis, 15(2); 525-537

Radnia, H., A. A. Ghoreyshi, H. Younesi, and G. D. Najafpour (2012). Adsorption of Fe(II) ions from aqueous phase by chitosan adsorbent: equilibrium, kinetic, and thermodynamic studies. Desalination and Water Treatment, 50(1-3); 348-359

Ravuru, S. S., A. Jana, and S. De (2019). Synthesis of NiAllayered double hydroxide with nitrate intercalation: Application in cyanide removal from steel industry effluent. Journal of Hazardous Materials, 373; 791-800

Shrestha, S. L. (2018). Study of the Adsorption Kinetics of Iron Ion from Wastewater Using Banana Peel. International Journal of Advanced Research Chemical Science, 5(3); 1-8

Siregar, P. M. S. B. N., N. R. Palapa, A. Wijaya, E. S. Fitri, and A. Lesbani (2021). Structural Stability of Ni/Al Layered Double Hydroxide Supported on Graphite and Biochar Toward Adorption of Congo Red. Science and Technology Indonesia, 6(2); 85-95

Taher, T., M. M. Christina, M. Said, N. Hidayati, F. Ferlinahayati, and A. Lesbani (2019). Removal of iron (II) using intercalated $\mathrm{Ca} / \mathrm{Al}$ layered double hydroxides with $[\alpha-$ SiW12O40] 4. Bulletin of Chemical Reaction Engineering $\mathbb{E}$ Catalysis, 14(2); 260-267

Tan, Y., X. Yin, C. Wang, H. Sun, A. Ma, G. Zhang, and N. Wang (2019). Sorption of cadmium onto Mg-Fe Layered Double Hydroxide (LDH)-Kiwi branch biochar. Environmental Pollutants and Bioavailability, 31(1); 189-197

Tang, Z., Z. Qiu, S. Lu, and X. Shi (2020). Functionalized layered double hydroxide applied to heavy metal ions absorption: A review. Nanotechnology Reviewes, 9(1); 800-819

Tyas, A. H., T. A. Zaharah, and A. Shofiyani (2018). Penentuan Kemampuan Penggunaan Ulang Komposit KitosanKarbon pada Proses Adsorpsi Ce (IV). Jurnal Kimia Khatulistiwa, 7(2)

Wang, L., A. Li, and Y. Chang (2016). Hydrothermal treatment coupled with mechanical expression at increased temperature for excess sludge dewatering: Heavy metals, volatile organic compounds and combustion characteristics of hydrochar. Chemical Engineering Journal, 297; 1-10 
Wazir, A. H., I. U. Wazir, and A. M. Wazir (2020). Preparation and characterization of rice husk based physical activated carbon. Energy Sources, Part A: Recovery, Utilization, and Environmental Effects; $1-11$

Zhang, Y., J. Zhao, Z. Jiang, D. Shan, and Y. Lu (2014). Biosorption of $\mathrm{Fe}(\mathrm{II})$ and $\mathrm{Mn}$ (II) Ions from Aqueous Solution by Rice Husk Ash. BioMed Research International, 2014;
$1-10$

Zubair, M., M. Daud, G. McKay, F. Shehzad, and M. A. AlHarthi (2017). Recent progress in layered double hydroxides (LDH)-containing hybrids as adsorbents for water remediation. Applied Clay Science, 143; 279-292 